\title{
DIAGNÓSTICO E TRATAMENTO DA ANEMIA FALCIFORME: REVISÃO DE LITERATURA
}

\section{DIAGNOSIS AND TREATMENT OF FALCIFORM ANEMIA: LITERATURE REVIEW}

\author{
Amanda Sousa Porto \\ Bacharel em Farmácia. Alfa - Faculdade de Almenara, Almenara-MG \\ Deise Maria de Jesus \\ Bacharel em Farmácia. Alfa - Faculdade de Almenara, Almenara-MG \\ Viviane Amaral Toledo Coelho \\ Doutora. vivianeatc@yahoo.com.br. Alfa - Faculdade de Almenara, Almenara-MG \\ Luiza Gobira Lacerda \\ Mestre em Zootecnia - Professor do curso de Farmácia UNIPAC \\ E-mail: lucioonofri@gmail.com \\ Luanna Botelho Souto de Araújo \\ Mestre em Zootecnia - Professor do curso de Farmácia UNIPAC \\ E-mail: lucioonofri@gmail.com
}

\section{RESUMO}

Objetivo: adquirir informações acerca da doença Falciforme, em seus diversos aspectos: detecção, tratamento e prevenção ou mesmo no acompanhamento do paciente e envolvimento com seus familiares. Metodologia: $O$ estudo foi realizado com avaliação de referencial bibliográfico de revistas, artigos e dissertações publicados entre o período de 2001 a 2018. Após uma leitura seletiva e minuciosa foram designados 39 estudos para compor a revisão bibliográfica. Sendo que 10 destes foram selecionados 
para integrar a descrição dos resultados e discussão. Resultados: No decorrer do estudo foi demonstrada a necessidade de uma conscientização mostrando como essa patologia gera um problema de saúde pública, por meio da base de dados. A necessidade de um acolhimento genético para casais que pretendem ter filhos é essencialmente para prepará-los psicologicamente e para que eles tenham conhecimento das diversas intervenções medicamentosas. Conclusão: Constatou-se que as pessoas com Anemia Falciforme apresentaram vários elementos favoráveis, em busca de adaptação ao adoecimento na fase adulta. Mesmo com tantas técnicas diagnósticas existentes, ocorre a necessidade de melhores metodologias diagnósticas, e também mais pesquisas, que por sua vez, viabilizariam novos tratamentos, proporcionando melhor qualidade e expectativa de vida aos portadores da doença Falciforme.

Palavras-chave: Anemia Falciforme. Diagnóstico. Prevenção e Controle. Fisiopatologia.

\section{ABSTRACT}

Objective: to acquire information about sickle cell disease, in its various aspects: detection, treatment and prevention or even in monitoring the patient and involvement with his family. Methodology: The study was carried out with the evaluation of bibliographic references of magazines, articles and dissertations published between 2001 and 2018. After a selective and thorough reading, 39 studies were designated to compose the bibliographic review. 10 of these were selected to integrate the description of the results and discussion. Results: Throughout the study, the need for awareness was shown, showing how this pathology generates a public health problem, through the database. The need for genetic reception for couples who intend to have children is essentially to prepare them psychologically and so that they are aware of the various drug interventions. Conclusion: It was found that people with sickle cell anemia had several favorable elements, in search of adaptation to illness in adulthood. Even with so 
many existing diagnostic techniques, there is a need for better diagnostic methodologies, and also more research, which, in turn, would enable new treatments, providing better quality and life expectancy for people with sickle cell disease.

Keywords: Sickle cell anemia. Diagnosis. Prevention and Control. Pathophysiology.

\section{INTRODUÇÃO}

De acordo com a Organização Mundial de Saúde (OMS), pode-se conceituar a anemia "como a condição na qual o conteúdo de hemoglobina no sangue está abaixo do normal, como resultado da carência de um ou mais nutrientes essenciais, seja qual for à causa dessa deficiência”. As anemias podem ser causadas por deficiência de vários nutrientes como Ferro, Zinco, Vitamina B12 e proteínas (BRASIL, 2004). Dentre os tipos de anemia existe a anemia falciforme (AF), que de acordo com Assunção, Barros e Santos (2017), é uma das doenças hereditárias mais comuns no mundo, sendo caracterizada pela "mutação gênica que ocasiona a substituição do aminoácido ácido glutâmico por valina na posição 6 da subunidade $\beta$ da hemoglobina que leva à produção da hemoglobina $\mathrm{S}(\mathrm{HbS})$, responsável pela hemácia adquirir essa forma de foice, daí o nome falciforme." No entanto a pessoa que herda apenas um gene modificado (heterozigoto) não desenvolve a doença e são chamados de portadores do "traço falciforme" (ASSUNÇÃO; BARROS; SANTOS, 2017).

Essa deformidade das hemácias ocorre, sobretudo sob condições de baixa oxigenação, fazendo com que ocorra um agrupamento das mesmas no vaso sanguíneo, impedindo dessa forma o fluxo do sangue nesse local, sendo exatamente essa alteração o fator determinante pelo sintoma principal na anemia falciforme: a crise de dor, que é muito intensa e requer hospitalização na maior parte dos casos. Em virtude dessa alteração estrutural, a hemácia tem meia-vida mais curta (aproximadamente 10-20 dias), causando a anemia (ASSUNÇÃO; BARROS; SANTOS, 2017).

No que se refere aos aspectos históricos, a AF foi reconhecida pela primeira vez em 1910, sendo sua maior incidência em povos de diferentes regiões da África, e em 
consequência, o Brasil, por apresentar uma população com diversas origens étnicas e com vários graus de miscigenação, assinalando que a presença da anemia falciforme é resultante da imigração de indivíduos descendentes, sobretudo do continente africano (BENFATO et al., 2007).

Tendo em vista os dados epidemiológicos da AF, a OMS estima que aproximadamente 1.900 crianças nasçam todos os anos no Brasil com Anemia Falciforme. Em conformidade com o Ministério da Saúde, "a doença é incidente em 2\% a 6\% da população residente nas regiões do país, nas quais a sua maioria portadora são indivíduos de origem afrodescendente, $6 \%$ a $10 \%$ dessa etnia tem a alteração genética, no Nordeste temos 3\% da população e 3,5\% dos Pernambucanos com a patologia. Devido à alta taxa de mortalidade, tem grande relevância sobre a área clínica, hematológica, bioquímica, genética, antropológica e epidemiológica" (MELO et al.,2017), e portanto, mediante essas altas taxas de prevalência da AF, no Brasil o diagnóstico passou a ser obrigatório em todos os estados da Federação. Teve início em 2001, a partir do Programa Nacional de Triagem Neonatal (PNTN) criado pela Portaria $n^{\circ}$ 822, do Ministério da Saúde, de 06/06/2001 e constitui medida positiva na redução da morbimortalidade da doença (GRADELLA; SABINO, 2016).

Frente à doença Falciforme é indispensável o envolvimento da família, uma vez que as pessoas acometidas com essa doença devem ter um cuidado intenso, bem como a prevenção de possíveis complicações e assim manterem um quadro clínico estável (BITTENCOURT et al., 2013). Portanto, com base nos aspectos supracitados sobre a $\mathrm{AF}$, compreende-se que é elementar o aconselhamento genético (para evitar que duas pessoas portadoras do traço falciforme tenham filhos com a doença), com implementação de testes de rastreamento dos portadores do traço, posto que os mesmos são completamente assintomáticos, mas têm $25 \%$ de chances de conceber uma criança com a doença (ASSUNÇÃO; BARROS; SANTOS, 2017).

Desta maneira o tratamento da AF consiste em anti-inflamatórios e derivados de opioídes contra a dor. A transfusão sanguínea e a Hidroxiuréia (HU) foram opções encontradas para tentar evitar as crises dolorosas e as complicações, como acidente vascular cerebral (AVC), priapismo, entre outros. A despeito dos possíveis efeitos 
adversos como a sobrecarga de ferro (no caso da transfusão) e mielosupressão (no caso da HU), a inserção dessas terapias mostrou-se bastante eficaz e com boa aceitação pelos pacientes (BRASIL, 2009).

A importância em pesquisar essa temática justifica-se, em razão de a AF ser uma patologia de caráter hereditário, sem cura. Deste modo, o diagnóstico precoce é de grande relevância, através do programa de triagem Neonatal e a busca de indivíduos heterozigotos na população em geral. Logo é muito importante a atuação do farmacêutico em direção à assistência do paciente portador da $\mathrm{HbS}$, e para isso ele precisa adquirir informações acerca da doença falciforme, em seus diversos aspectos: detecção, prevenção e tratamento ou mesmo no acompanhamento do paciente e envolvimento com seus familiares. Deve também o farmacêutico estar envolvido em programas e projetos direcionados aos portadores do gene da $\mathrm{HbS}$. Uma participação ativa desse profissional poderá diminuir a morbidade e mortalidade por causa da doença (FREITAS; PEREIRA, 2008). A partir dessas reflexões, esse estudo teve como objetivo pesquisar, através de publicações científicas, e traçar um panorama da AF, bem como suas complicações, possíveis diagnósticos e tratamento, em razão de ser uma patologia que acomete uma parcela significativa da população.

\section{METODOLOGIA}

Trata-se de revisão integrativa da literatura, sendo do tipo exploratório - descritivo método que viabiliza a análise de pesquisas científicas de modo sistemático e amplo, contribuindo para a caracterização e divulgação do conhecimento produzido. A pesquisa bibliográfica é feita a partir do levantamento de referências teóricas já analisadas, e publicadas por meios escritos e eletrônicos, como livros, artigos científicos, páginas de web sites (FONSECA, 2002).

Para a escolha do tema proposto foi indagado a seguinte questão norteadora: Por ser uma doença hereditária, não ter cura e apresentar-se como um grande problema de saúde pública mundial, surgiu-se o interesse por abordar quais os principais 
diagnósticos e formas de tratamento da Anemia Falciforme?

O estudo foi realizado com avaliação de referencial bibliográfico de revistas, artigos e dissertações publicados entre o período de 2001 a 2018. Após uma leitura seletiva e minuciosa foram designados 39 estudos para compor a revisão bibliográfica. Sendo que 10 destes foram selecionados para integrar a descrição dos resultados e discussão. Foram utilizados para as buscas, os bancos de dados PubMed, SCIELO - Scientific Electronic, Biblioteca Digital de Teses e Dissertações e Google Acadêmico.

$\mathrm{Na}$ seleção dos artigos resultantes da pesquisa científica foram utilizados os seguintes critérios: o interesse para o tema, os artigos científicos e estudos escritos em português, com data de publicação nos últimos 16 anos ou de anos anteriores, se o conteúdo fosse relevante. No decorrer do estudo foram utilizados os seguintes descritores: Anemia Falciforme, diagnóstico, prevenção e controle, fisiopatologia.

\section{CONCEITO E EPIDEMIOLOGIA DA ANEMIA FALCIFORME}

A Anemia Falciforme foi descoberta por Herrick, no ano de 1910, e foi encontrada primeiramente na Ásia Menor, estendendo-se pela África, e acomete atualmente cerca de $40 \%$ de toda a população (SILVA, 2015).

Entende-se que a AF é uma doença de caráter genético, que tem como característica a presença da hemoglobina $S$, proteína mutante que sofre polimerização e deforma-se, assumindo forma de foice. A AF é incluída no grupo de Doenças Falciformes (DF) sendo uma das mais prevalentes hemoglobinopatias. Sua presença reduz a velocidade da circulação sanguínea, ocasionando crises dolorosas, vaso oclusão e isquemia, além da hemólise precoce crônica (FELIX; SOUZA; RIBEIRO, 2010).

Diante dessa exposição, AF é uma doença genética comum no Brasil e no mundo, sendo mais prevalente entre descendentes de negros. A mutação gênica provoca a substituição do aminoácido ácido glutâmico por valina na posição 6 da subunidade $\beta$ da hemoglobina que leva à produção da $\mathrm{HbS}$, responsável pela hemácia adquirir essa forma de "foice", daí o nome falciforme. Os indivíduos que herdam apenas um gene 
modificado (heterozigotos) não desenvolvem a doença e são chamados de portadores do traço falciforme (ASSUNÇÃO; BARROS; SANTOS, 2017).

Quanto àlinha falciforme não que se falar em alterações hematológicas, as ações vaso-oclusivos sob condições fisiológicas, inexistem, desencadeando na não mortalidade nem morbidade seletivas (BENFATO et al., 2007). Todas as formas sintomáticas do gene da $\mathrm{HbS}$, em homozigose ou em combinação, são conhecidas como doenças falciformes, mesmo que as particularidades se distinguem nos graus variados de gravidade, toda doença tem sua particularidade. O histórico vem dos pais, que são portadores assintomáticos de um único gene afetado (heterozigotos), produzindo $\mathrm{HbA} \mathrm{e}$ $\mathrm{HbS}$ (AS), transmitindo cada um deles, o gene alterado para a criança, que recebe o gene anormal em dose dupla (homozigoto SS). O gene da HbS pode combinar-se com outras anormalidades hereditárias das hemoglobinas, como hemoglobina $\mathrm{C}(\mathrm{HbC})$, hemoglobina $\mathrm{D}(\mathrm{HbD})$, beta-talassemia, entre outros, gerando combinações que também são sintomáticas, denominadas, respectivamente, hemoglobinopatia SC, hemoglobinopatia SD, S/beta- talassemia (CORRÊA, 2016).

O nível sócio-econômico deve ser levado em consideração, já que a doença evolui de forma branda em pacientes com melhor alimentação e melhores oportunidades de tratamento. Os portadores da Anemia Falciforme estão carentes de um fortalecimento no aspecto social, com intuito de viabilizar recursos para aumentar a renda da família, como a ministração de cursos profissionalizantes gratuitos, pois ainda não existem iniciativas específicas para essa população, seja na rede pública ou na privada (CASTELO et al., 2012).

\section{MANIFESTAÇÃO CLÍNICA E SINTOMAS DA ANEMIA FALCIFORME}

O fenômeno de afoiçamento das hemácias é responsável por todo o quadro fisiopatológico. As hemácias, quando assumem essa forma, apresentam maior rigidez e vivem na circulação sanguínea em média 10 dias, muito menos que o tempo médio usual de 120 dias, estando mais sujeitas à destruição. Isso resulta em anemia crônica 
intensa (BRASIL, 2006).

Os principais sinais clínicos observados são decorrentes da forma afoiçada das hemácias. Esse formato influencia intensamente no fluxo do sangue da microcirculação, pois a irregularidade da superfície de contato das hemácias alteradas permite reações químicas interativas entre estas e as células endoteliais, fazendo-as aderir à parede do vaso sanguíneo. As consequências da aderência são caracterizadas pela vaso-oclusão, com redução do fluxo do sangue nos capilares, causando estases venosa e hipóxia, que acarretam crises agudas intensamente dolorosas e lesão tecidual orgânica crônica e progressiva (BRASIL, 2016).

O quadro de anemia ocorre quando há diminuição no número de hemácias circulantes no sangue. As hemácias falciformes do indivíduo que tem AF são hemolisadas constantemente, diminuindo a concentração sanguínea de hemoglobina. A AF pode ocasionar vários tipos de sintomas em indivíduos portadores dessa enfermidade, como crises vaso- oclusivas, precipitadas por infecção, acidose, desidratação e desoxigenação; crises de sequestro visceral, ocasionadas por deformação falciforme dos eritrócitos e retenção do sangue em órgãos; crises aplásticas, causada principalmente por deficiência de folato; e, a mais famosa, crise hemolítica, caracterizada por aumento do ritmo de hemólise com queda de hemoglobina e aumento de reticulose (MELO et al., 2017).

Um estudo realizado por Araújo, Bellato, Silva (2013), relata que os portadores revelaram que as dores são sintomas marcantes em suas vidas, intensas, muitas vezes persistentes e que restringem bastante seu cotidiano.

A Crise vaso-oclusiva é definida como a admissão hospitalar por episódio doloroso na ausência de outra causa, que não a doença de base, requerendo uso de medicação narcótica (ARAÚJO, et al., 2004). A maior incidência de internação dos pacientes com $\mathrm{AF}$ acontece devido às crises vaso-oclusivas, não possuindo uma prevenção específica, salvo os casos nos quais o medicamento hidroxiuréia pode diminuir a frequência de crises, que caracterizam-sepela evolução de complicações agudas, em crianças e adolescentes e nos adultos. As formas de prevenção secundária podem diminuir o número de internações, mas não chegam a ser capazes de torná-las "eletivas" (LOUREIRO; ROZENFELD, 2005). 
A instalação da hidratação venosa é um aspecto importante na assistência ao paciente com crises de dor. Sua recomendação é para controle da crise vaso-oclusiva e o equilíbrio hídrico quanto à infusão de medicação analgésica e caracteriza-se como principal cuidado. A hidratação deve ser cautelosa pelo risco de sobrecarga cardíaca e estudos revelam que além da perda de água, a hipostenúria (Sinal de insuficiência renal caracterizado por urina de baixa densidade e pouco concentrada.) é a anormalidade mais comum em indivíduos com a Anemia Falciforme (BRITO; MIRANDA, 2016).

Um dos principais sinais da Anemia Falciforme é a Crise Álgica, pois ocorrem inesperadamente, em alguns casos após uma crise infecciosa, um resfriamento súbito ou estresse físico e/ou emocional afetando diretamente a qualidade de vida do paciente. Essas crises podem ser agudas, subagudas ou crônicas, geralmente acompanhadas de febre com edema e calor na área. Em alguns casos as crises podem durar de 4 a 6 dias ou até mesmo semanas, considerando o fator de risco como febre alta, desidratação, palidez, vômitos, dores e priapismo. Tais crises tendem a atingir 37\% das mulheres no seu período menstrual. (JUNIOR, 2017).

A transfusão sanguínea durante a crise álgica para reduzir a necessidade do uso de opióides, é um estudo promissor recente, o qualdeterminou que a transfusão de glóbulos vermelhos empacientes diminuía o tempo de internação e os requisitos de opióides, se comparado ao tratamento padrão. O resultado foi favorável na redução do tempo de internação e utilização de opióides (BRITO MIRANDA, 2016).

A pessoa com doença falciforme tem a dor como parte constante da evolução da doença, sendo causa de internações ao longo da vida dessas pessoas. A crise aguda de dor ou crise álgica manifesta-se comumente a partir dos 24 meses de vida e é responsável pela maioria dos casos de atendimento de emergência e hospitalização, assim como pela má qualidade de vida dos pacientes acometidos, e internações frequentes, que resultam em elevada mortalidade (SANTOS ,2014).

O sequestro esplênico instala-se subitamente, havendo queda progressiva nos valores sanguíneos de hemoglobina, sendo uma complicação aguda da maior gravidade, causadora de grande morbidade e mortalidade em pacientes com doença falciforme. É a partir dos 5 meses de vida, até os 2 anos que ela se desenvolve mais comumente. Sua 
manifestação clínica caracteriza-se por súbito mal estar, e seu estado piora progressivamente, entre a palidez e dor abdominal, acompanhados de sudorese, taquicardia e taquipnéia. Estabelece-se muitas vezes por estar associado a infecções virais ou bacterianas. Em aproximadamente $20 \%$ dos casos a síndrome torácica aguda acompanha o quadro (BRUNIERA,2007).

A segunda causa de internação e mortalidade em pacientes com Deficiência Falciforme é a Síndrome Torácica, e sua ocorrência tem mais intensidade em crianças pequenas (ARAÚJO, 2011). A síndrome Torácica aguda se manifesta de acordo com a idade, e crianças são mais propícias a apresentar tosse e febre. Já os adultos apresentam maior dificuldade na respiração e dor no tórax. As radiografias mostram que em crianças não há preferência quanto ao lobo dos pulmões, enquanto nos adultos ambos são afetados. Nos adultos, em torno de $9 \%$ dos casos resultam em morte, e em crianças, menos de $1 \%$. No entanto, há necessidade de um exame clínico mais detalhado, uma vez que $40 \%$ dos casos se mostram sem alteração (JUNIOR, 2017).

Na Doença Falciforme o priapismo é definido pela ereção peniana prolongada e dolorosa não acompanhada de desejo ou estímulo sexual, usualmente persistente por mais de quatro horas. Esta condição é considerada uma emergência urológica e, infelizmente, a disfunção erétil é sequela comum no tratamento inadequado.

Há que se falar em dois tipos de priapismo: baixo fluxo (isquêmico) e alto fluxo (não isquêmico). A forma típica de priapismo em pacientes portadores de doença falciforme é a de baixo fluxo, podendo ocorrer de modo agudo ou recorrente, sendo o priapismo recorrente caracterizado por episódios durante o sono, onde não ocorre detumescência ao acordar. Em geral, dura menos de três horas (FIGUEIREDO, 2007).

\section{DIAGNÓSTICO DA ANEMIA FALCIFORME}

Ressalta-se que o principal diagnóstico da DF é pela triagem neonatal (teste do pezinho), antes do aparecimento dos sintomas clínicos, que encoraja a implementação de práticas de cuidados preventivos e orientação aos pais em relação ao recém-nascido. 
Permite também uma ação pedagógica sobre a condição genética da família e risco de recorrência em futuras gestações, através de orientação familiar ou aconselhamento genético (BRASIL, 2016).

Através da portaria $n^{\circ} 822 / 01$, o Ministério da Saúde instituiu o Programa Nacional de Triagem Neonatal (PNTN), e a triagem para a $\mathrm{HbS}$ foi incluída neste programa, além da fenilcetonúria e do hipotireoidismo, devido: as doenças falciformes (SS, SC e ST) serem doenças que não apresentam características clínicas precoces; serem de fácil detecção laboratorial e economicamente viáveis; permitirem testes de alta sensibilidade e especificidade; apresentarem sinais e sintomas que podem ser reduzidos ou eliminados com a instituição do tratamento eterem a necessidade de um programa de acompanhamento após o diagnóstico.O diagnóstico precoce da anemia falciforme, através do Teste do pezinho, permite o acompanhamento dos pacientes antes das manifestações e da sintomatologia e, com isto, a prevenção das complicações e sequelas (ALMEIDA et al., 2009).

O Teste de Falcização consiste em colocar o eritrócito a ser pesquisado, sob baixa tensão de oxigênio; o eritrócito contendo $\mathrm{Hb} \mathrm{S}$ toma a forma de foice ou meia- lua, ometabissulfito de sódio reduz a tensão de oxigênio, quando uma solução de metabissulfitode sódio é acrescentada ao sangue total, e essa mistura e lacrada entre lamina e lamínula, por meio de esmalte, os eritrócitos contendo $\mathrm{Hb} \mathrm{S}$ se deformam. $\mathrm{O}$ teste de falcizaçãoéinespecífico para o recém-nascido, por levar a resultados falsonegativos aos altos níveis de hemoglobina fetal e aos baixos níveis da hemoglobina $S$ presentes nesta ocasião (DUPSKI, 2017).

O teste de solubilidade baseia-se no fato de que, sob baixas concentrações de oxigênio, a $\mathrm{Hb} \mathrm{S}$ torna-se 100 vezes menos solúvel que sua forma oxigenada. No entanto, o teste de solubilidade não apresenta boa sensibilidade para detecção da presença de $\mathrm{Hb} \mathrm{S}$ no período neonatal, especialmente nos RN prematuros, uma vez que neste período ainda não houve a transição de $\mathrm{Hb} \mathrm{F}$ para hemoglobina do adulto. Nessa faixa etária, até mais ou menos os seis meses de idade, um teste de solubilidade negativo deve ser interpretado com cautela, principalmente se feito por ocasião de uma emergência (BANDEIRA et al., 2003). 
A eletroforese, é uma técnica simples para a detecção rápida de hemoglobinopatias, em acetato de celulose, $\mathrm{pH}$ alcalino, amplamente difundida, é uma metodologia que deve ser utilizada como teste de rastreamento inicial para a detecção de hemoglobinas variantes (ZAMARO et al., 2001). A inclusão da eletroforese de hemoglobina, nos testes de triagem neonatal, representou um passo importante no reconhecimento da relevância das hemoglobinopatias, como problema de Saúde Pública no Brasil, e o início da mudança da história natural da doença em nosso país. A repetição da eletroforese confirma o perfil hemoglobínico num melhor momento, ocasião em que se aproxima do perfil do adulto (FIGUEIREDO et al., 2014).

\section{TRATAMENTO DA ANEMIA FALCIFORME}

Ainda não existe tratamento específico para a doença, porém alguns procedimentos preventivos ou paliativos são adotados para diminuir seus efeitos, tais como: fármacos como a 5-azicitidina, que utilizam-se de moléculas covalentes (isocianatos e clofibrato), suplementação com arginina, fito medicamentos, transfusões sanguíneas regulares, medicamentos quelantes de ferro, introdução da hidroxiuréia. Os pacientes acometidos pela anemia falciforme apresentam susceptibilidade às infecções, sendo assim importante a vacinação desses contra as principais patologias (ALMEIDA; BERETTA, 2017).

Diante de tal constatação Marques et al. (2015) aborda que, o ideal é que o tratamento seja iniciado antes dos quatro meses de vida, para que a prevenção das infecções e outras complicações que podem levar à morte da criança, seja efetiva. A família da criança identificada deverá receber orientação básica da equipe multidisciplinar no ponto de atenção especializado, para a confirmação diagnóstica e o início do tratamento específico. A prevenção das complicações é muito eficiente na redução da morbimortalidade. As principais medidas preconizadas para alcançar esse objetivo são: antibióticoterapia profilática (esquema especial de vacinação). Os medicamentos que compõem a rotina de tratamento e integram a farmácia básica são: 
ácido fólico (uso contínuo), penicilina injetável (obrigatoriamente até os cinco anos de idade), antibióticos, analgésicos e anti-inflamatórios (usados nas intercorrências).

Evidencia-se com maior clareza, que além das manifestações clínicas, como em outras doenças, os sinais e sintomas da DF causam repercussão em vários aspectos da vida das pessoas, como a interação social, as relações conjugais e familiares, a educação e o emprego. Embora essas manifestações sejam intensas, podem ser prevenidas e tratadas, garantindo às pessoas longevidade com qualidade. $\mathrm{O}$ transplante de medula óssea tem sido praticado em centros de pesquisa, e definido por protocolos para esse fim, o que faz com que haja pessoas indicadas e outras, não, para tal procedimento (MARQUES et al., 2015).

As fortes crises de dor que decorrem da vaso-oclusão são comuns, segundo a OMS, e o esquema de tratamento segue por degraus. O $1^{\circ}$ degrau são analgésicos não opióide (dipirona, acetominofen, AAS, paracetamol), antiinflamatórios não esteroidais (AINEs: AAS, diclofenaco, indometacina, ibuprofeno) e adjuvantes (anticonvulsivantes, antidepressivos, neurolépticos, benzodiazepínicos e anticolinérgicos). O $2^{\circ}$ degrau é composto de opioídes fracos (codeína, tramadol), AINEs, adjuvantes. O $3^{\circ}$ degrau Opioíde potente (morfina, fentanila, metadona, oxicodona), AINEs, adjuvantes (JUNIOR, 2017).

A Hidroxiuréia é um quimioterápico que atua como antifalcização, aumentando a hemoglobina fetal nas células e reduzindo as chances de aparecimento de tromboses e das crises dolorosas intensas, atuando na modificação da membrana dos eritrócitos, diminuindo os neutrófilos e a expressão de moléculas de adesão em linfócitos e monócitos. Tem situações em que a utilização de hidroxiuréia pode provocar mielodepressão e pancitopenia, sendo necessária uma atenção especial em relação ao número de granulócitos, plaquetas e reticulócitos durante a sua utilização (SANTOS,2014).

Sabe-se que a transfusão de hemácias possui apenas algumas contraindicações bem específicas, ou seja, em transfusões de substituição total em recém-nascidos (sobretudo em prematuros), em pacientes com anemia falciforme em crise de falcização e em indivíduos sob hipóxia intensa. Portanto,o mais conveniente seria investigar a presença 
da hemoglobina $\mathrm{S}$ diretamente no produto hemoterápico a ser usado (sangue total ou concentrado de hemácias), através de testes pré-transfusionais, já que existem testes capazes de demonstrar a presença da hemoglobina $\mathrm{S}$ em poucos segundos, sem exigir qualquer aparelhagem especializada (COELHO; GUIMARÃES, 2010).

O Transplante de Medula Óssea, vem se constituindo como uma alternativa de tratamento para diversos tipos de neoplasias, doenças hematológicas ou não, doenças metabólicas e deficiências imunológicas, compondo o quadro de diagnósticos que recebem indicações para o TMO tem-se, dentre outros a anemia falciforme (MASTROPIETRO;SANTOS;OLIVEIRA. 2006).

Com relação aos tratamentos, não podemos deixar de falar do transplante de medula óssea, é considerada a cura, pois há a substituição da série vermelha,não pode deixar de falar que há muitos riscos com grandes porcentagens de mortalidade e complicações. As melhores pessoas para realizarem o transplante são menores de 18 anos, e que não tenha nenhum problema grave como lesão hepática, pulmonar ou cardíaca, aloimunização e depósitos de ferro excessivos (SANTOS, 2014).

\section{ATENÇÃO FARMACÊUTICA A PACIENTES COM ANEMIA FALCIFORME}

De acordo com Pereira e Freitas (2008), a atenção farmacêutica é o componente da prática profissional onde o farmacêutico interage diretamente com o paciente para atender suas necessidades relacionadas ao medicamento e diagnóstico, proporcionando impacto positivo no controle de patologias crônicas, associado à redução de custos para o sistema de saúde, os quais podem nortear a implantação e implementação desse serviço em todo país.

Reafirmando a relevância, trata-se de uma atividade multiprofissional e idealizada no contexto de atenção integral à saúde, num modelo que privilegia a promoção da saúde, tendo como principal objetivo garantir a integralidade das ações de saúde, incluindo-se o acesso com qualidade aos medicamentos e seu uso racional (CONSENSO BRASILEIRO DE ATENÇÃO FARMACÊUTICA, 2002).

Entre esses atores encontra-se o farmacêutico, por ter acesso a informações completas 
a respeito da segurança dos fármacos, como também identificar e prevenir corretamente combinações entre as substâncias farmacológicas constantes nos medicamentos. A primeira escolha do doente, que não encontra no sistema de saúde o serviço necessário, é buscar no farmacêutico a orientação amiga, franca, desinteressada e segura. Isso só eleva a responsabilidade ética e profissional do farmacêutico, que é o último elemento, e às vezes, o único, da equipe de saúde, que possui contato com o doente antes que ele tome um medicamento. Diante desta realidade, torna-se necessária a preparação adequada do profissional farmacêutico para o atendimento correto, devendo ter o conhecimento de análiseslaboratoriais e diagnósticas das doenças falciformes (FREITAS; PEREIRA 2008).

Os exames clínicos laboratoriais são solicitados pelo médico para um melhor diagnóstico, e é importante que o profissional que realiza as análises laboratoriais efetue uma correta interpretação e correlacione os resultados com o estado clínico, repetindo testes duvidosos, até mesmo para um controle de qualidade mais efetivo. Por isso é importante o conhecimento do farmacêutico sobre os sintomas da anemia falciforme e a emissão de exames precisos para detecção da doença (SILVA; SHIMAUTI, 2006).

Muitas vezes o diagnóstico tardio de uma doença congênita torna-se um problema que atualmente é uma realidade de saúde pública, principalmente quando reconhecido na adolescência ou no início da idade adulta. Mesmo havendo um serviço assistencial de aconselhamento genético, os programas de diagnóstico neonatal da anemia falciforme, visando o início do tratamento dos 6 meses de idade, são excepcionais no Brasil. O diagnóstico precoce, sobretudo ao nascimento, e o tratamento adequado, melhoram a taxa de sobrevivência e a qualidade de vida dos doentes com a anemia falciforme (FREITAS; PEREIRA, 2008).

O sucesso da terapêutica e do prognóstico do paciente depende dos cuidados realizados pela equipe multiprofissional. A integração e boa comunicação entre os membros da equipe assistencial é fator primordial para a segurança do paciente. Os resultados reforçam a importância do farmacêutico na equipe multidisciplinar, como o profissional responsável pelo uso seguro dos medicamentos (NOVAIS et al., 2009).

Afinal é muito importante a ação do farmacêutico em direção à assistência do 
paciente portador da $\mathrm{HbS}$, visto que de acordo com o Ministério da Saúde (MS), a doença falciforme requer muitos cuidados, devidoà alta prevalência na população brasileira, inclusão das hemoglobinopatias nos testes de triagem neonatal, alto grau de morbidade e de mortalidade passíveis de prevenção, importância médico-social do início precoce do tratamento, necessidade de tratamento multidisciplinar realizado por profissionais treinados e a necessidade de formular políticas específicas para os indivíduos por ela acometidos (MAXIMO, 2009).

\section{RESULTADOS E DISCUSSÃO}

Os estudos encontrados condizentes aos aspectos da presente revisão foram 39 e 10 aproveitados para proceder à pesquisa. A tabela 1 apresenta informações sobre o título, periódico, país de publicação e ano dos artigos incluídos nesta revisão.

Tabela 1: Informações dos artigos incluídos na revisão bibliográfica.

\begin{tabular}{|c|c|c|c|c|}
\hline Título do Artigo & Periódico & $\begin{array}{l}\text { País de } \\
\text { Publicação }\end{array}$ & Idioma & Ano \\
\hline $\begin{array}{l}\text { Anemia falciforme: uma revisão } \\
\text { acerca da doença, novos métodos } \\
\text { diagnósticos e tratamento. }\end{array}$ & $\begin{array}{l}\text { Revista Eletrônica Acervo Saúde, v. } \\
9 \text {, p. } 856-863 \\
2017\end{array}$ & Brasil & Português & 2017 \\
\hline $\begin{array}{l}\text { Anemia falciforme e seus aspectos } \\
\text { psicossociais: O olhar do doente e } \\
\text { do cuidador familiar }\end{array}$ & $\begin{array}{l}\text { Revista Cuidarte-Programade } \\
\text { Enfermaria UDSS. P.2, } 2013 .\end{array}$ & Brasil & Português & 2013 \\
\hline $\begin{array}{l}\text { Diagnostico da Hemoglobina } \\
\text { S:análise comparativa do teste de } \\
\text { solubilidade com aeletroforese em } \\
\text { pH alcalino e ácido no período } \\
\text { neonatal }\end{array}$ & $\begin{array}{l}\text { Rev. Brasil Saúde Matern. Infant, } \\
\text { Recife, p.02, } 2008 .\end{array}$ & Brasil & Português & 2003 \\
\hline $\begin{array}{l}\text { Principais técnicas para o } \\
\text { diagnostico da anemia falciforme: } \\
\text { Uma revisão de literatura }\end{array}$ & $\begin{array}{l}\text { Ciências Biológicas e de Saúde Unit } \\
\text { - Facipe, v. 3, n. 2, p. 33-46, nov, } \\
2017 .\end{array}$ & Brasil & Português & 2017 \\
\hline $\begin{array}{l}\text { Anemia falciforme: Abordagem } \\
\text { diagnostica laboratorial }\end{array}$ & $\begin{array}{l}\text { Rev. Ciênc. Saúde Nova Esperança, } \\
\text { p.04, } 2014 \text {. }\end{array}$ & Brasil & Português & 2014 \\
\hline
\end{tabular}




\begin{tabular}{|c|c|c|c|c|}
\hline $\begin{array}{l}\text { A fisiopatologia da Anemia } \\
\text { falciforme }\end{array}$ & $\begin{array}{l}\text { Rev. Infarma v.19, n. 1/2, p. 1-3-6, } \\
\text { jan. } 2007\end{array}$ & Brasil & Português & 2007 \\
\hline $\begin{array}{l}\text { Eficácia e toxicidade da } \\
\text { Hidroxiuréia em crianças com } \\
\text { anemia falciforme }\end{array}$ & $\begin{array}{l}\text { Revista Brasileira } \\
\text { Hematologia Hemoter, v. 28, n.2, } \\
\text { São José do Rio Preto } \\
\text { abr./jun, } 2006\end{array}$ & Brasil & Português & 2006 \\
\hline $\begin{array}{l}\text { Anemia Falciforme: Um panorama } \\
\text { atual da doença. }\end{array}$ & $\begin{array}{l}\text { Universidade de Brasília Faculdade } \\
\text { de Ciências da Saúde Departamento } \\
\text { de } \\
\text { Farmácia, 2017, pg. } 21 .\end{array}$ & Brasil & Português & 2017 \\
\hline $\begin{array}{l}\text { Anemia Falciforme: Diagnóstico e } \\
\text { tratamento }\end{array}$ & $\begin{array}{l}\text { Faculdade de Educação e Meio } \\
\text { Ambiente, 2015, pg. } 20 .\end{array}$ & Brasil & Português & 2017 \\
\hline $\begin{array}{l}\text { Perfil de pessoas com doença } \\
\text { falciforme em uma unidade de } \\
\text { emergência: implicações para o } \\
\text { cuidado de enfermagem }\end{array}$ & $\begin{array}{l}\text { Universidade } \\
\text { Fluminense Escola de Enfermagem } \\
\text { Aurora de Afonso Costa. p. 18, } \\
\text { Niterói-RJ. }\end{array}$ & Brasil & Português & 2014 \\
\hline
\end{tabular}

Fonte: Autores (2019).

A tabela 2 apresenta a síntese dos artigos integrados com as seguintes informações: objetivo, metodologia, resultados e importância do diagnóstico e tratamento para qualidade de vida dos pacientes com Anemia Falciforme.

Tabela 2: Caracterização da síntese dos artigos incluídos na revisão bibliográfica.

\begin{tabular}{l|l|l|l}
\hline Objetivos & Metodologia & $\begin{array}{l}\text { Resultados } \\
\text { Importância do diagnóstico e } \\
\text { tratamento para qualidade } \\
\text { de vida dos pacientes com } \\
\text { Anemia Falciforme }\end{array}$ \\
\hline
\end{tabular}




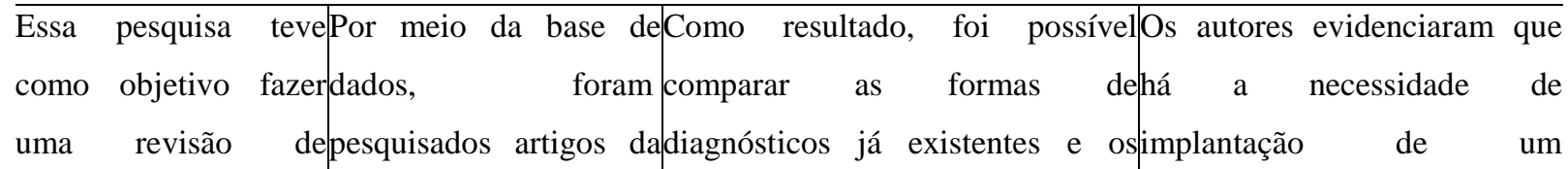

literatura atual sobre aliteratura medica danovos testes rápidos, descartáveis, rastreamento de neonatal anemia falciforme, língua inglesa ede baixo custo, que vem sendoprecoce. O surgimento de novos métodos portuguesa, de janeirodesenvolvido e sua importância emnovos testes mais rápidos, de diagnósticos e de 1996 a outubro deregiões carentes para ummenor custo.

tratamento. 2016, que se diagnóstico precoce e início de

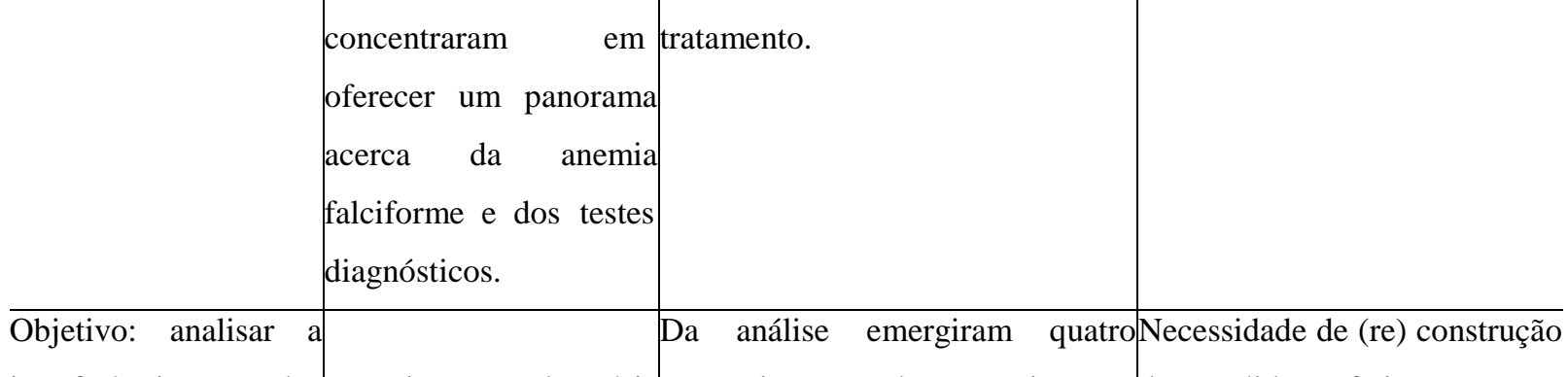
interferência dos Pesquisa exploratóriacategorias, a saber: sentimentos de medidas efetivas para o aspectos psicossociais descritiva com relacionados à condição crônica dacontrole de desordens no nível de qualidade abordagem qualitativa,doença; relações sociais; vivendopsicossociais que interferem de vida dos portadores realizada num com a anemia falciforme e suasnegativamente na qualidade de de anemia falciforme município a $197 \mathrm{~km}$ delimitações; conhecimento dos vida dos portadores de AF. e de seus familiares/Salvador, Bahia, Brasil. familiares sobre anemia cuidadores. falciforme.

O sangue de cordãoA eletroforese de $\mathrm{Hb}$ em $\mathrm{PH} A$ eletroforese de $\mathrm{Hb}$ em $\mathrm{PH}$ umbilical de 1988 alcalino detectou a presença de Hbalcalino mostrou-se eficaz mo recém-nascidos $(\mathrm{RN})$ naS em $105 \quad(5,3 \%)$ amostras. Addiagnóstico da hemoglobina $\mathrm{S}$ maternidade do Institutoanálise destas 105 amostras através no período neonatal, podendo Materno-Infantil deda eletroforese em PH ácidoser utilizado nos locais onde Pernambuco (IMIP), mostrou que 98 (93,3\%)técnicas mais sofisticadas não Avaliar a eficácia dodurante o períodomantiveram o mesmo padrãolestão implantadas. $\mathrm{O}$ teste de teste de solubilidadeloutubro de 1996 aeletroforético. O teste delsolubilidade não serve como como método demarço de 1997, foilsolubilidade detectou apenas umabordagem diagnóstica para a triagem na detecção de submetido

\section{$\mathrm{Hb} \quad \mathrm{S}$ no períodoeletroforese}

à $\mathrm{RN}$ portador de $\mathrm{Hb} \mathrm{S}$.

neonatal, hemoglobina em $\mathrm{PH}$ técnicas de solubilidade.

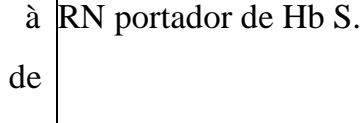

presença de $\mathrm{Hb} \mathrm{S}$ no período neonatal. 


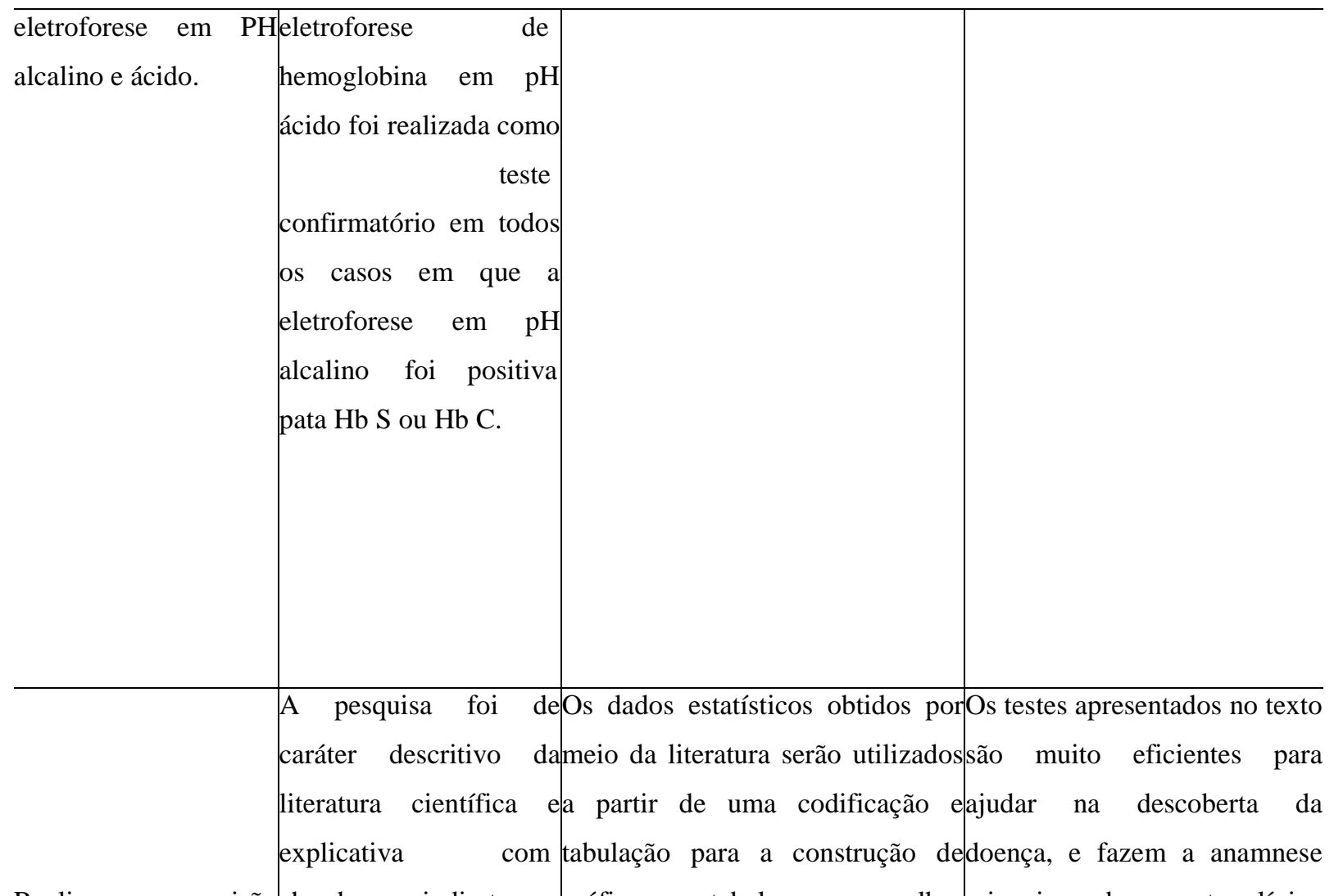

Realizar uma revisãolabordagem indireta, nagráficos e tabelas para melhorminuciosa do aspecto clínico de literatura de caráterqual foram coletadoscompreensão da descritivo explicativoartigos nas plataformasabordada.

\begin{tabular}{|c|c|}
\hline $\begin{array}{l}\text { das técnicas utilizadas } \\
\text { no diagnóstico dessa } \\
\text { enfermidade. }\end{array}$ & $\begin{array}{l}\text { virtuais } \\
\text { acadêmico, } \\
\text { pottal Capes, Bieme, } \\
\text { Biblioteca da Faculdade } \\
\text { Integrada } \\
\text { Pernambuco e sites } \\
\text { relacionados à saúde, no } \\
\text { período de janeiro a } \\
\text { julho de 2017. }\end{array}$ \\
\hline
\end{tabular}

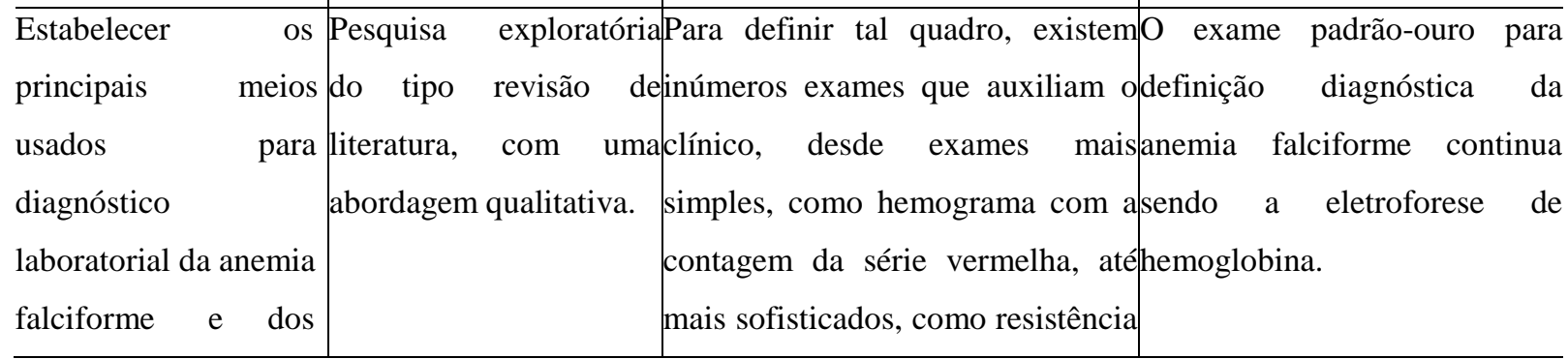




\begin{tabular}{|c|c|c|c|}
\hline $\begin{array}{l}\text { portadores destes } \\
\text { traços. }\end{array}$ & & $\begin{array}{l}\text { osmótica em solução de cloreto de } \\
\text { sódio a } 0,36 \% \text {. }\end{array}$ & \\
\hline $\begin{array}{l}\text { É relatar a } \\
\text { fisiopatologia } \\
\text { anemia } \\
\text { doença } \\
\text { mais } \text { falciforme, } \\
\text { Brasil, que apresenta } \\
\text { sérias mam, no } \\
\text { clínicas e constitui um } \\
\text { problema de saúde } \\
\text { pública, no País. }\end{array}$ & & $\begin{array}{l}\text { A polimerização da } \mathrm{Hb} \text { S é } \\
\text { dependente da tensão de oxigênio, } \\
\text { concentração intracelular da } \mathrm{Hb} \mathrm{S}, \\
\text { temperatura e associação com } \\
\text { outras hemoglobinas e talassemias. }\end{array}$ & $\begin{array}{l}\text { A anemia falciforme é uma } \\
\text { doença que está presente no } \\
\text { mundo todo, sendo } \\
\text { considerado um problema de } \\
\text { saúde pública inclusive no } \\
\text { Brasil. Desordens hereditárias } \\
\text { da hemoglobina, se não } \\
\text { tratadas, resultam em morte } \\
\text { nos primeiros anos de vida. }\end{array}$ \\
\hline $\begin{array}{l}\text { Avaliar por meio da } \\
\text { revisão literária, os } \\
\text { riscos, benefícios } \\
\text { efeitos adversos da } \\
\text { Hidroxiuréia } \\
\text { crianças. }\end{array}$ & & 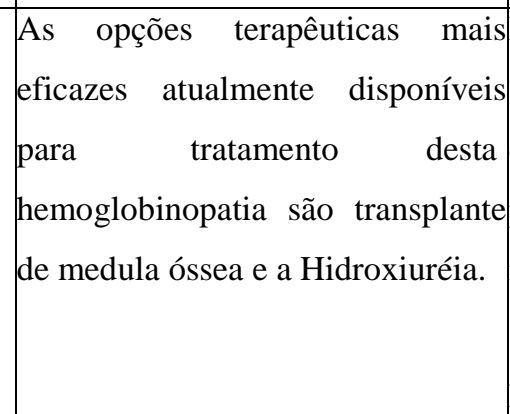 & $\begin{array}{l}\text { Estima-se ainda que haja } \\
700.000 \text { novos casos anuais de } \\
\text { doenças falciformes, sendo, } \\
\text { portanto, consideradas como } \\
\text { importante problema de } \\
\text { saúde } \\
\text { pública. }\end{array}$ \\
\hline $\begin{array}{l}\text { Revisar a literatura a } \\
\text { fim de apresentar uma } \\
\text { atualização sobre a } \\
\text { AF. }\end{array}$ & Revisão de literatura. & $\begin{array}{l}\text { Apesar das dificuldades quanto a } \\
\text { achar um doador compatível para } \\
\text { realização do transplante de } \\
\text { células tronco. }\end{array}$ & $\begin{array}{l}\text { Os profissionais de saúde têm } \\
\text { um grande papel na } \\
\text { disseminação da informação } \\
\text { desde a importância da triagem } \\
\text { neonatal. }\end{array}$ \\
\hline $\begin{array}{llr}\text { Retratar } & \text { sobre } & \mathrm{o} \\
\text { diagnóstico } & & \mathrm{e} \\
\text { tratamento } & \text { da } & \text { anemia } \\
\text { falciforme. } & \end{array}$ & Revisão de literatura & $\begin{array}{l}\text { A necessidade de um acolhimento } \\
\text { genético para casais que } \\
\text { pretendem ter filhos é } \\
\text { essencialmente para prepará-los } \\
\text { psicologicamente e para que eles } \\
\text { tenham conhecimento das diversas } \\
\text { intervenções } \\
\text { medicamentosas. }\end{array}$ & $\begin{array}{l}\text { Eecessáriauma } \\
\text { Conscientização mostrando } \\
\text { pomo essa patologia gera um } \\
\text { problema de saúde pública. }\end{array}$ \\
\hline
\end{tabular}




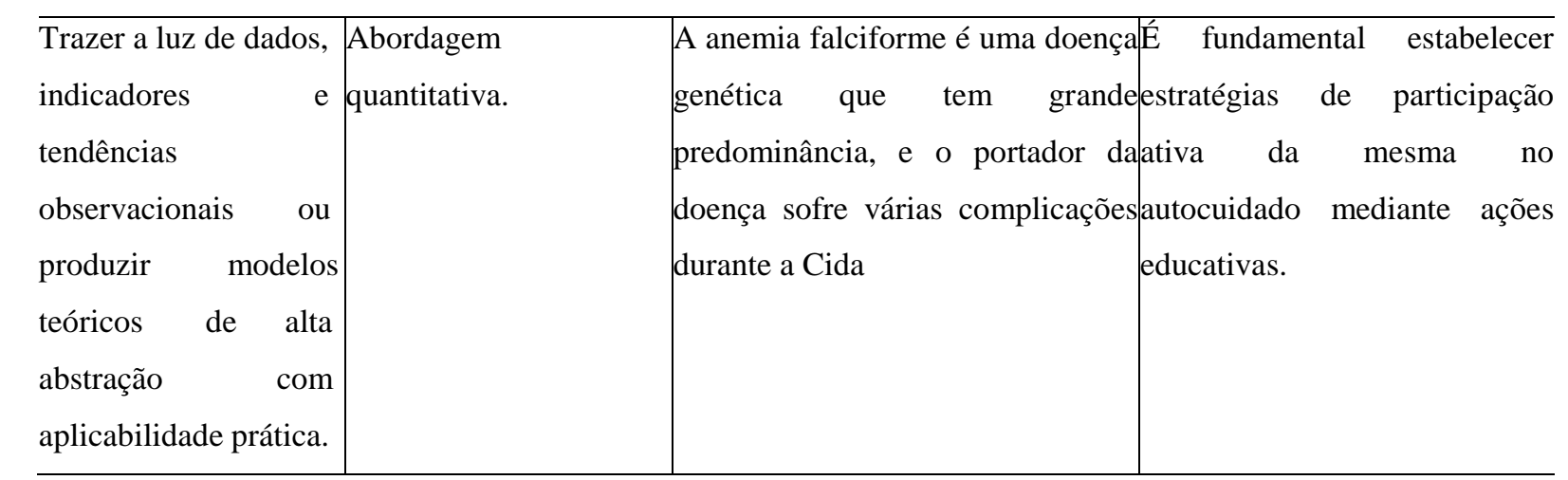

Fonte: Autores (2019).

O estudo 1 e 9, através de uma revisão de literatura, retratou que, quanto ao diagnóstico e tratamento da anemia falciforme, é necessário uma conscientização mostrando como essa patologia gera um problema de saúde pública, por meio da base de dados. Foram pesquisados artigos da literatura médica da língua portuguesa, que se concentraram em oferecer um panorama acerca da anemia falciforme e dos testes diagnósticos.

A necessidade de um acolhimento genético para casais que pretendem ter filhos é essencial para prepará-los psicologicamente e para que eles tenham conhecimento das diversas intervenções medicamentosas.

No artigo 2 foi feita uma pesquisa exploratória descritiva com abordagem qualitativa, realizada num município a $197 \mathrm{~km}$ de Salvador, Bahia, Brasil, onde da análise emergiram quatro categorias, a saber: sentimentos relacionados à condição crônica da doença; relações sociais; vivendo com a anemia falciforme e suas limitações; conhecimento dos familiares sobre anemia falciforme.

Na pesquisa 3, durante o período de outubro de 1996 a março de 1988, recémnascidos (RN) na maternidade do Instituto Materno-Infantil de Pernambuco (IMIP), foram submetidos à eletroforese de hemoglobina em $\mathrm{pH}$ alcalino $\mathrm{e}$ ao teste de solubilidade. Bandeira et al (2003) salienta que a eletroforese de $\mathrm{Hb}$ em PH alcalino detectou a presença de $\mathrm{Hb} \mathrm{S}$ em 105 (5,3\%) amostras. A análise destas 105 amostras através da eletroforese em P.H ácido mostrou que 98 amostras (93,3\%) mantiveram o mesmo padrão eletroforético. O teste de solubilidade detectou apenas um RN portador 
de $\mathrm{Hb} \mathrm{S}$.

Os testes apresentados no texto são muito eficientes para ajudar na descoberta da doença, fazem a anamnese minuciosa do aspecto clínico da patologia é coagir com o médico, para prognóstico de grande eficiência. No estudo 4, os dados estatísticos obtidos por meio da literatura serão utilizados a partir de uma codificação e tabulação para a construção de gráficos e tabelas, para melhor compreensão da temática abordada.

O estudo 5 buscou estabelecer os principais meios usados para diagnóstico laboratorial da anemia falciforme e dos portadores destes traços. Para definir tal quadro, existem inúmeros exames que auxiliam o clínico, desde exames mais simples, como hemograma com a contagem da série vermelha, até mais sofisticados, como resistência osmótica em solução de cloreto de sódio a $0,36 \%$.

Este estudo 6 visou relatar a fisiopatologia da anemia falciforme, doença monogênica mais comum no Brasil, e que apresenta sérias manifestações clínicas e constitui um problema de saúde pública no país, abordando que a polimerização da $\mathrm{Hb} \mathrm{S}$ é dependente da tensão de oxigênio, concentração intracelular da $\mathrm{Hb} \mathrm{S}$, temperatura e associação com outras hemoglobinas e talassemias.

O estudo 7 e o 10 demonstram que as opções terapêuticas mais eficazes atualmente disponíveis para tratamento desta hemoglobinopatia são transplante de medula óssea e a Hidroxiuréia. A doença em questão é considerada como importante problema de saúde pública e é fundamental estabelecer estratégias de participação ativa da mesma no autocuidado, mediante ações educativas.

Apesar das dificuldades quanto a achar um doador compatível para realização do transplante de células tronco, o estudo 8 aponta que os profissionais de saúde têm um grande papel na disseminação da informação, desde a importância da triagem neonatal.

Felix, Souza e Ribeiro (2010) explica que a anemia falciforme é uma doença genética e sua principal característica é a presença da hemoglobina $S$, e um dos principais efeitos clínicos da DF é a redução da velocidade das hemácias na circulação sanguínea, ocorrendo crises dolorosas. Quanto às manifestações clínicas, os estudos revelam que tais sinais são decorrentes da forma afoiçada das hemácias. Esse formato influencia intensamente no fluxo do sangue da microcirculação, pois a irregularidade da superfície 
de contato das hemácias alteradas permite reações químicas interativas entre estas e as células endoteliais, fazendo-as aderir à parede do vaso sanguíneo (BRASIL, 2016).

\section{CONCLUSÕES}

Dentre as diversas hemoglobinopatias existentes, nacional e mundialmente, a mais comum é a anemia falciforme, sendo esta considerada um problema de saúde pública. É uma doença hereditária transmitida dos pais para os filhos, com maior frequência em pessoas da raça negra.

Existem inúmeros testes laboratoriais, tanto qualitativos, como quantitativos, utilizados no diagnóstico da mesma, alguns empregados como forma de triagem da doença, como, hemograma, teste de falcização, teste de solubilidade, focalização isoelétrica e eletroforese de hemoglobina.

O maior conhecimento da base biológica dessas doenças, ainda associadas à elevada morbimortalidade, tem propiciado importantes avanços nas abordagens terapêuticas e na prevenção de novos casos e pode, em um futuro próximo, oferecer possibilidades mais concretas de cura. Talvez as medidas utilizadas para que a doença se torne conhecida não sejam tão efetivas. É necessária a conscientizaçãoda sociedade para um problema que afeta boa parte da população, principalmente aqui no Brasil.

Os profissionais de saúde também têm um grande papel na disseminação da informação, desde a importância da triagem neonatal, sobre o que é a doença e em casos de possíveis filhos com a doença, levar ao alcance o aconselhamento genético como forma de prevenção de novos casos.

Dentre os profissionais de saúde está o farmacêutico que, por ter acesso a informações completas a respeito da segurança dos fármacos, tem como identificar e prevenir corretamente combinações entre as substâncias farmacológicas constantes nos medicamentos, e o doente, quando se encontra com alguma dificuldade sua primeira escolha é buscar no farmacêutico a orientação amiga, franca, desinteressada e segura, a responsabilidade ética e profissional do farmacêutico se eleva, pois este é, às vezes, o 
último ou o único elemento da equipe de saúde que possui contato com o doente, antes que ele tome um medicamento.

\section{REFERÊNCIAS BIBLIOGRÁFICAS}

ALMEIDA, R. A.; BERETTA, A. L. R. Z. Anemia Falciforme e abordagem laboratorial: uma breve revisão de literatura. Revista Brasileira de Análises Clínicas, v. 49, n. 2, p. 131-134, 2017.

ALMEIDA, C, M. et al. Muito além do "Teste do Pezinho". Revista Brasileira de Hematologia e Hemoterapia,v. 31, n. 2, p. 88-93, 2009.

ARAÚJO, A. Q. Síndrome torácica aguda: revisão geral atualizada e uma proposta de protocolo para diagnóstico e conduta. Secretaria de Estado de Saúde do Distrito Federal - Hospital Regional da Asa Sul - Residência Médica em Pediatria, 2011.

ARAÚJO. A. S. et al. Hidroxiuréia em pacientes com síndromes falciformes acompanhados no Hospital Hemope. Revista Brasileira de Hematologia e Hemoterapia, v. 26, n. 3,2004.

ARAÚJO, L. F. S; BELLATO, R. SILVA, A. H. Cotidiano da família que experiência a condição crônica por anemia falciforme. Revista Eletrônica de enfermagem, v. 15, n. 2, p. 437-46, 2013.

ASSUNÇÃO, B. R; BARROS, S. A. F; SANTOS, C. C. D. Anemia falciforme: uma revisão acerca da doença, novos métodos diagnósticos e tratamento. Revista Eletrônica Acervo Saúde, v. 9, p. 856-863, 2017.

BANDEIRA. F. M.G. C. et al. Diagnóstico da hemoglobina S: analise comparativa do teste de solubilidade com a eletroforese em $\mathrm{PH}$ alcalino e ácido no período neonatal. Revista Brasileira de Saúde Materno Infantil, v. 3, n. 3, p. 265-270, Recife, 2003.

BENFATO, M., S. et al. A fisiopatologia da Anemia Falciforme. Revista Infarma, v. 19, n. 1/2, p. 3-6, 2007. 
BITTENCOURT.I. S. et al. Anemia Falciforme e seus aspectos psicossociais: o olhar do doente e do cuidador familiar. Revista Cuidarte-Programa de Enfermaria UDSS, 2013.

BRUNIERA. Crise de sequestro esplênico na doença falciforme. Rev. bras. hematol. Hemoter, v 29.n.3. p. 259-261, 2007.

BRASIL.Ministério da Saúde. Dicas em saúde, dez. 2004. Disponível em: <http://bvsms.saude.gov.br/bvs/dicas/69anemia.html>. Acesso em: 10 abr 2019.

Ministério da Saúde. Secretaria de Atenção à Saúde. Departamento de Atenção Especializada. Manual de condutas básicas na doença falciforme / Ministério da Saúde, Secretaria de Atenção à Saúde, Departamento de Atenção Especializada. Brasília: Editora do Ministério da Saúde, 2006.

Ministério da Saúde. Secretária de Atenção à Saúde. Departamento de Atenção Especializada. Manual de Educação em Saúde - Linha de Cuidado em Doença Falciforme. Série A. Normas e Manuais Técnicos. Brasília, 2009.

Ministério da Saúde. Secretaria de Atenção à Saúde. Departamento de Atenção Especializada e Temática. Triagem neonatal biológica: manual técnico / Ministério da Saúde, Secretaria de Atenção à Saúde, Departamento de Atenção Especializada e Temática. - Brasília: Ministério da Saúde, 2016.

Ministério da Saúde. Secretaria de Atenção à Saúde - Secretaria de Ciência, Tecnologia e Insumos Estratégicos. Portaria n 05, do Ministério da Saúde, de 19 de fevereiro de 2018. Aprova o Protocolo Clínico e Diretrizes Terapêuticas da Doença Falciforme. Diário Oficial da República Federativa do Brasil. Brasília, 19 de fev. de 2018.

BRITO M, B. MIRANDA, F, P. A assistência multidisciplinar ao paciente com anemia falciforme na internação de crises álgicas - uma revisão integrativa. Revista Enfermagem Contemporânea, v.5, n.1, p. 143-150, jan./jun. 2016.

CASTELO, N, M, L. et al., Anemia falciforme sobre o olhar de pessoas com a doença no Amapá. Revista Ciência Equatorial, v. 2, n. 2, p. 1-6, 2012.

COELHO, G. O; GUIMARÃES, C, T, L.A importância do aconselhamento genético na anemia falciforme. Revista Ciências e Saúde Coletiva, v. 15, n. 1, p. 1733-1744, 2010. 
CONSENSO BRASILEIRO DE ATENÇÃO FARMACÊUTICA - PROPOSTA.

Atenção

Farmacêutica no Brasil: "Trilhando Caminhos". Brasília: Organização Pan-Americana da Saúde, 2002.

CORRÊA, M. V. A. Parâmetros Laboratoriais no Diagnóstico da Anemia

Falciforme: Uma revisão. Universidade Regional do Noroeste do Estado do Rio Grande do Sul, Ijuí, 2016.

DUPSKI. D. S. Anemia falciforme: diagnóstico e tratamento. Faculdade de Educação e Meio Ambiente, Ariquemes, 2017.

FELIX, A. A.; SOUZA, H. M.; RIBEIRO, S. B. F. Aspectos epidemiológicos e sociais da doença falciforme. Revista Brasileira Hematologia e Hemoterapia, v. 32, n. 3, p. 203-208, 2010.

FIGUEIREDO. A, K, B. et al. Anemia falciforme: abordagem diagnóstica laboratorial. Revista Ciências e Saúde Nova Esperança, v. 12, n. 1, p. 96-103, 2014.

FIGUEIREDO. V. Priapismo na doença falciforme. Rev. bras. hematol. Hemoter, v. 29, n.3, p.275-278, 2007.

FONSE CA, J.J.S. Metodologia da pesquisa científica. Apostila - Universidade Estadual do Ceará. Fortaleza, 2002.

FREITAS, O. A; PEREIRA, L.R.L. Evolução da Atenção Farmacêutica e a perspectiva para o Brasil. Revista Brasileira Ciências Farmacêuticas, v. 44, n. 4, p. 601-612, 2008.

GRADELLA, D. B. T. SABINO, M. F.Perfil epidemiológico de pacientes internados por doença falciforme no estado do Espírito Santo, Brasil (2001-2010). Revista Brasileira Pesquisa Saúde, Vitória, v. 18, n. 2, p. 35-41, abr-jun, 2016.

JUNIOR. N. G. M. Anemia Falciforme: Um panorama atual da doença. Universidade de Brasília Faculdade de Ciências da Saúde Departamento de Farmácia, 2017. 
LOUREIRO, M, M. ROZENFELD, S. Epidemiologia de internações por doença falciforme no Brasil. Revista Saúde Pública, v. 39, n. 6, p. 943-9, 2005.

MARQUES, L. N. et al. O viver com a doença falciforme: percepção de adolescentes. Revista de Terapia Ocupacional da Universidade de São Paulo, v. 26, n. 1, p. 10 17, jan./abr., 2015.

\section{MASTROPIETRO, A. P.; SANTOS, M. A.; OLIVEIRA, E. A. Sobreviventes do}

transplante de medula óssea: construção do cotidiano. Rev. Ter. Ocup. Univ. São Paulo, v. 17, n. 2, p.64-71, maio/ago., 2006.

MÁXIMO. C. A Política de Atenção Integral à Pessoa com Doença Falciforme no Estado do Rio de Janeiro e os Desafios da Descentralização. Fundação Oswaldo Cruz, 2009.

MELO. M.G.N. et al. Principais técnicas para o diagnóstico da anemia falciforme: uma revisão de literatura. Revista Ciências Biológicas e de Saúde, v. 3, n. 2, p. 33-46, nov, 2017.

NOVAES, M. R. C. G. et al. Guia de Boas Práticas em Farmácia Hospitalar e Serviços de Saúde - Sbrafh. São Paulo: Ateliê Vide o Verso, 2009.

NOVAIS, T. S. Perfil demográfico da doença falciforme, 2009. Disponível em: $<$ http://portal.saude.gov.br/portal/arquivos/pdf/doenca_falciforme_Novais_pop_negra. pdf $>$ www.portalsaude.gov.br/portal/arquivos/pdf/doenca_falciforme_Novais_Popnegra-pdf $>$. Acesso em: 20 de maio 2019.

SANTOS, A, L. Perfil de pessoas com doença falciforme em uma unidade de emergência: implicações para o cuidado de enfermagem. Universidade Federal Fluminense, Niterói, 2014.

SILVA, E. Anemia Falciforme: Caracterização Geral. Universidade Federal do Paraná. Foz do Iguaçu, 2015.

SILVA, M. C.; SHIMAUTI, E. L. T. Eficácia e toxicidade da hidroxiuréia em crianças com anemia falciforme. Revista Brasileira Hematologia Hemoterapia, v. 28, n. 2, p.144-8, abr./jun, 2006. 
ZAMARO. P. J. A.; CANALLI. A., A. JÚNIOR. W., A., S. DOMINGOS. C., R., B. Diagnóstico laboratorial de hemoglobinas semelhantes à HbS. Jornal Brasileiro de Patologia e Medicina Laboratorial. p. 261-6, jun, 2001. 